\title{
Initial experience with the providence nighttime bracing in adolescent idiopathic scoliosis
}

\author{
Inge Beuschau ${ }^{1 *}$, Lena Quisth', Ane Simony ${ }^{2}$ \\ From 11th International Conference on Conservative Management of Spinal Deformities - SOSORT 2014 \\ Annual Meeting \\ Wiesbaden, Germany. 8-10 May 2014
}

\section{Background}

Nearly six years ago the primary conservative treatment of adolescent idiopathic scoliosis (AIS) in the southern part of Denmark, went from full time bracing and hospitalization to nighttime bracing and an in- and outpatient treatment.

\section{Aim}

To evaluate the effectiveness of nighttime bracing in AIS.

Methods: Inclusion criteria were patients diagnosed with AIS and skeletal immature. With an apex of the primary curve from $\mathrm{TH} 7$ and below and with a Cobb angel between 20- 45 degrees. The patients were asked to wear the brace at least 7-8 hours pr. night.

No other previous treatments were accepted and a follow up at least 6 months out of brace. The brace treatment was continued until two years post menarche or for male at the expected adult height.

Cross-measured $\mathrm{x}$-rays were used to compare the primary Cobb angel, the in-brace correction and the outcome Cobb angel. A decreased outcome Cobb angle as well as the overcorrection of the curve measured in brace was recorded as zero.

The brace treatment was considered failed if progression $>5$ degrees occurred and if surgery were performed.

\section{Results}

A total of 55 patients, 8 male and 47 female, with a mean age at 14 years (11-16.5) and the mean primary Cobb at 31 degrees (20-41) were included in this study. There were 27 primary thoracic curves, 16 thoracolumbar, 11 lumbar and 1 double curve.
The mean time of treatment was 18 month (5-59).

The average in-brace correction was $81 \%$ (24-100\%), with a mean in-brace Cobb of 6,1 degrees (0-26). After ended treatment the mean Cobb angle was 28 degrees (7-50), an average of no progression. The end results were 11 failures (6-15 degrees); equal $20 \%$ and out of these 11 patients, 3 had surgery performed (5\%).

\section{Conclusion}

The results show a good curve control and an acceptable $20 \%$ failure rate, which is equal to other studies. The providence brace is an excellent alternative to standard conservative treatment. Larger studies are needed to establish the relationship between in-brace correction and curve progression during the treatment.

\section{Authors' details}

'ORTOS, Odense, Denmark. ${ }^{2}$ Sector for Spine Surgery and Research, Middelfart Hospital, Denmark.

Published: 4 December 2014

\section{References}

1. Yriönen T, Ylikoski M, Schlenzka D, Kinnunen R, Poussa M: Effectiveness of the Providence nighttime bracing in adolescent idiopathic scoliosis: a comparative study of 36 female patients. Eur Spine J 2006, 15(7):1139-1143.

2. Weinstein S, Dolan LA, Wright J, Dobbs MB: Effects of Bracing in Adolescent with Idiopathic Scoliosis. N Engl J Med 369(16):1512-1521.

doi:10.1186/1748-7161-9-S1-033

Cite this article as: Beuschau et al:: Initial experience with the providence nighttime bracing in adolescent idiopathic scoliosis. Scoliosis 2014 9(Suppl 1):033. 